\title{
Actual strategies of interaction between government bodies and mining enterprises: personnel problems
}

\author{
Natalia Zaruba ${ }^{1}$, Mariana Petrova ${ }^{2 *}$, Konstantin Vostrikov ${ }^{1}$, Eduard Wolfson ${ }^{1}$, and Olga \\ Nikiforova ${ }^{1}$ \\ ${ }^{1}$ EDP Sciences, Kuzbass State Technical University named after T. F. Gorbachev, Kemerovo, Russia \\ ${ }^{2}$ EDP Sciences, St.Cyril and St.Methodius University of Veliko Tarnovo
}

\begin{abstract}
The subject of research in this article is the search for possible strategies to overcome the shortage of personnel for the mining industry. The purpose of the study is to prepare recommendations that will help implement HR strategies in mining companies. Method of research. The study used comparative and institutional approaches, as well as an empirical method - the method of observation. Research materials. When preparing the scientific article, the materials of reports of specialized structures of regional government bodies and reports of the rector of the Kuzbass state technical University were used. The results obtained will help to improve the rating indicators of mining enterprises for attracting qualified personnel. The study shows that only an integrated approach to the application of ethical HR technologies can make real progress in a reasonable time frame. The problem of reducing the number of trained specialists and the professionalism of personnel in the mining industry in the Kemerovo region remains particularly relevant. In this situation, there is an appeal of managers of industrial enterprises to educational institutions of any level to develop strategies to solve the personnel problems that have arisen. These managers have a desire to solve personnel issues together with the leading training centers in Kuzbass. The government of the Kemerovo region, the relevant ministries and the Kuzbass State Technical University constantly receive written requests to the rector to develop a personnel strategy for a specific enterprise. Following the instructions of the regional leadership, various departments of the University conduct research on personnel problems at the enterprise and offer their own strategies for overcoming them. The Department of state and municipal management conduct research with enterprises on the managerial aspect of personnel work related to interaction with state authorities in the region. Thanks to working contacts with the profile structures of regional management bodies, there is a constant personnel monitoring at problem enterprises with the involvement of employees of the Department. Based on the results of monitoring, detailed reports are compiled, which can be
\end{abstract}

\footnotetext{
${ }^{*}$ Corresponding author: m.petrova@ts.uni-vt.bg
} 
considered as the basis for developing personnel strategies that can be implemented by both public authorities and mining enterprises themselves.

\section{Introduction}

To date, according to many researchers, the domestic mining industry shows a trend towards sustainable functioning and development, despite the pandemic and crisis, and has, in general, favorable prospects, despite the forecast of others that the stability of the energy market as a whole is not so favorable. This market is experiencing some serious difficulties due to falling demand for coal. At the same time, there are a number of acute problems that hinder the development of the mining industry, including the problem of a shortage of modern and competent personnel.

We emphasize that none of the current problems can be solved only by economic or political means. There is an underestimation of the role of public administration as an effective lever in to solve the problem of the lack of competent and highly professional personnel trained for modern conditions of functioning not only of society and the state in General, but also of the mining industry, in particular, in the direction of its digitalization, automation and robotization.

The need for highly qualified and competent modern personnel in the mining industry is one of the main problems for the economy of our country in the conditions of the emerging economic market and crisis, as it is a key aspect of all other problems that are present today in the domestic structure of production forces (Bulletin of the TRANS-Baikal mining College named after M. I. Agoshkov, 2017.

The epoch of innovative development of the Russian mining industry market character can not present new challenges to vocational education as the main factor in the formation of a new quality, as an important condition for ensuring the well-being and future lifestyle of the country in which this industry is one of their key provisions. Russia is becoming a country of a new economy, a market economy, and the task of the vocational education system is to develop in accordance with these modern realities. Currently, the problem of inconsistency between the requirements of the innovative economy for a specialist in the mining industry and the system of training in higher education institutions in the country is becoming more acute. To implement innovative activities in the mining industry, we need specialists who possess the competencies necessary for innovation, to manage innovation processes in it. In connection with the orientation of the national education system to a competence approach and the transition to a new generation of standards, the focus is on the formation of key competencies of specialists that ensure personal mobility in a rapidly changing world and professional success in the innovative nature of the development of the mining industry. The process of implementing this model does not match the pace of change occurring in the industry. The country still does not have an effective system of vocational education, the main problem of which is a delayed response to changes, while it should be ahead of the curve and prepare specialists for the level of tomorrow's development of the mining industry for at least a period of 5 to 10 years. The relevance of search of the bases of effective training of specialists for innovation in the mining sector due to several circumstances:

- significant changes in domestic and foreign education systems under the Bologna process; - the specifics of the period that Russian society is experiencing, due to the change in the social and economic path of development of the state, its transition to a market-based development mechanism;

- significant changes in the national system of professional education, its modernization in the direction of compliance with the development of the country's innovative economy; 
- the need to train innovative specialists with innovative competencies necessary for the innovative development of the mining industry.

Modern trends in the development of the country's mineral resource complex, its leading role in the formation of industrial and economic potential determine the state and main directions for improving the national system of training specialists. The policy implemented by the state, University centers of higher mining education, leading companies and financial and industrial groups in the field of development of human resources of mining enterprises, in turn, determines for many years not only the pace, but also the nature of the development of many sectors of the economy of the country and regions. The quality of its formation determines the effectiveness of the development of geo-resources, the direction and pace of development of modern technologies and equipment in the mining industry, the level of safety and technical equipment of its specialists - all that determines the innovative nature of the development of mining enterprises and the economy as a whole.

The analysis of scientific and theoretical bases and legal documents of training specialists for the mining industry in the conditions of innovative, market economy in the country allowed us to come to the conclusion that currently there are two models of education: "supportive" and "innovative". (Chupryakova, Zakonnova \& Petrova, 2020; Kolechkina et al, 2019; Petrova, Tepavicharova, Dikova, 2018; Petrova et al, 2020). Professional education, as "supporting", is understood by the authors as a process and result of educational activities aimed at maintaining or reproducing the existing culture, social system, social experience, as well as its preservation and inheritance. "Innovative" education is supposed to stimulate the desire of future specialists to make changes in the existing culture, social sphere, economy, etc. on the basis of existing best traditions. in order to create a new competitive product, bring it to the consumer and, as a result, improve the quality of life of society" (Gerasimov\&Ilyukhina, 1999; Buzko et al, 2016; Linde\& Petrova, 2018; Jarmusevica et al, 2019A; Jarmusevica et al, 2019B; Gryshova et al, 2019; Zagorodnya et al, 2020; Zhernov, Nekhoda, Petrova, 2020).

In our opinion, the basic characteristics of University-type higher education institutions, Foundation, and also acquaintance of students with the relevant scientific aspects, the development of the principles and techniques of educational and scientific-research work give graduates significant advantages for quality implementation of the ideas of the innovation economy and have, to some extent, traits of "innovative" education.

At the same time, in our opinion, University education, first of all, clearly shows a trend of pragmatism and focus, first of all, on providing personnel for the modern market economy: creating business incubators, research and production centers, etc., which is inherent in all the same about "supporting" education.

Second, modern standards of the GEF IN not found attention position about the importance of training specialists for the mining industry to professional activity in the innovation sector of the industry. This is confirmed by the fact that such competence as readiness and ability to operate in the conditions of the innovative sector of the industry is not fully reflected in this document. It defines different types of specialist activities (production and technological, organizational and managerial, research and design), but such activities as innovation were not included. Only one specialization out of twelve in the direction of "mining" (underground development of reservoir deposits), as a professional competence (PC) involves the formation of "readiness to develop innovative technological solutions".

And, third, the analysis of the structure of the OOP of specialist training ("Mining" 130400) of the Federal state educational system (2011) in the list of mandatory disciplines for program development did not reveal the fundamental scientific direction for training a specialist for the innovative mining industry - "Innovatika" (Krechetov, 2019). While studying the documents of the Federal state educational system in A number of other 
specialties reveals an interesting fact: the following competencies belong to the General cultural competence (OC):

- ability to understand the role of innovation in the development of society and science (OK-1); - the ability to acquire and use in practice new knowledge and skills, including in areas not directly related to the field of activity (OK-4);

- the ability to choose a research method, modify existing methods and develop new ones based on the tasks of a specific study (OK - 5) and a number of others. It turns out that the mining industry in the Russian Federation will not receive specialists competent in the field of innovation in the coming years with all the consequences of this.

Also alarming is the fact that open, for example, in KuzGTU specialty "innovation" (27.03.05 GEF IN) and stated quite rightly, as a profession of the future, virtually no demand. I think that this direction should be a priority for University education, which is most likely due to in-depth training for research and educational research activities is closer to solving the problem of training specialists for the innovative mining industry, without which the question of the whole innovative society is questionable.

Thus, the identified problems require finding ways to solve it, and the main idea is to strengthen the interaction of government bodies with mining enterprises on the basis of an integrative approach. Interaction between the mining industry and the higher education system has always been relevant, but we are talking about the need to strengthen interaction, that is, integration.

In this situation, it is extremely important not only to actively form an understanding of the University's mission in modern society in the public consciousness and government authorities, but also to develop a system of University education to train specialists with the innovative competence necessary for the development of the innovative Russian mining industry. In our case, we are talking about the formation of a specialist who is able and ready to work in an innovative mining industry, as well as able and ready to carry out innovative activities in the existing innovative sector of this industry.

In our opinion, a specialist in the conditions of innovative development of the mining industry should not only have a mind, talent, outstanding skills and other competencies in their profession, which are fixed in the state standard of higher education. We agree with the authors ' position that this is now hopelessly insufficient to ensure that in a unique situation, he could not act according to the template that every profession is rich in. He must do something that in this situation, no one else will do. At the same time, he should do this not according to the rules, but creatively, apply all his abilities at once in this unique situation. (Konkova, 1996).

In this regard, the training of specialists for the innovative mining industry requires the implementation in the system of professional education not only changes in the content of education, its innovative orientation, but also innovative educational technologies. Traditional lectures should be replaced in the educational process by forms of teaching students based on a competency-based approach to the organization of the educational process, which orients the teacher to create conditions for including students in various types of productive, research, experimental, and innovative activities, contributing to the formation of a specialist who is able and ready to innovate in the industry.

In our opinion, there are contradictions in the training of specialists at the University for the innovative sector of the mining industry:

- there is a high level of theoretical research on the problems of professional education and insufficient knowledge of the development of modern approaches and theories of training specialists for the innovative sector of the mining industry;

- the need to train specialists for the innovative sector of the mining industry, which is confirmed by its real existence, and the insufficient level of development of its theoretical and methodological justification; 
- high innovative potential of modernization of the professional education system and lack of theoretical developments that allow for scientific training of specialists for the innovative sector of the country's mining industry;

* significant potential for innovative development of professional education of specialists and insufficient development of conceptual and technological bases for training specialists in the system of higher professional education.

The innovative way of development is inherent in almost all branches of the domestic economy, including mining. According to experts, " one of the main strategic directions that can increase the level of competitiveness of a mining enterprise is innovative technological development - increasing the level of efficiency and safety of production through continuous improvement of technical devices, technological processes, organizational changes that ensure the commercial effectiveness of innovations" (Zaruba, 2016; Zaruba, Egorova \& Kosinskij, 2017; Zaruba, Nikiforova\&Vostrikov, 2020). However, technological development will not happen without specialists who are ready for this.

Traditional, "supportive" education or professional development, we believe, will not provide significant changes in the level of training for the innovative mining industry. We need a qualitatively different approach to training specialists, focused on the introduction of various types of innovations (Pakhomova, 2013). The modern mining industry needs a specialist who will rely not only on instructions, but also enter professional life with the already established creative, research experience acquired at the University, necessary for innovation in the field of Economics, with competence in the field of innovation.

Kuzbass is one of the main centers of mining development, and training for the mining industry is a priority for the entire professional community (Strategy of socio-economic development of the Kemerovo region until 2035). The forecast for the development of the Kuzbass coal industry sets the region new quantitative and qualitative tasks for the development of the personnel training system, taking into account the long-term needs of enterprises for specialists. Even with a General analysis, it can be seen that the current educational programs of higher education institutions are more focused on training highly qualified specialists in the mining industry. Much attention and a significant part of the training time is devoted to theoretical training, the study of the device and operation of technological equipment within certain disciplines, and very little space is given to the organization of operation, maintenance, repair, i.e., those issues that the potential employer pays most attention to. This allows us to speak again about the "supporting" nature of higher education, rather than about innovative education.

Every year in Russia, about five thousand people graduate in mining specialties. This is enough to close the industry's need for specialists. At the same time, over the past 15-20 years, the number of employees has been steadily decreasing every year due to increased efficiency of production management, labor productivity, and the introduction of new technologies. For example, in the coal industry-almost six times. Universities, accordingly, have begun to train fewer specialists in unclaimed specialties, some areas of training for the management of mining universities have to close. However, if you compare today's statistics with the figures of twenty or thirty years ago, it is wrong to talk about a shortage of specialists. KuzSTU meets the needs of enterprises in the region by $30 \%$. Unfortunately, in the process of training, the loss of the contingent is $34 \%$. The industry constantly being transformed, and the share of human participation in many production cycles is decreasing. This situation can be changed in many ways due to effective state management of the Russian education system, both University and postgraduate, in particular, in the subsystem of industry management. The specifics of the formation of a system of postgraduate training of civil servants in branch management is that it, being a subsystem of the civil service, serves it and trains professional personnel. Russian researcher O. M. Konkova, 
based on this, identifies several tasks that allow us to take into account the world and domestic experience to combine theory and practice in the training of specialists in the field of mining management (Konkova, 1996). One of these tasks is that when preparing mining engineers for open - pit mining, it is important today to involve practitioners - highly qualified and experienced employees of coal mines, mines and processing plants, as well as power engineers-in educational activities. Such specialists are primarily able to convey to students the horizons of innovation in the mining industry, identify existing problems and outline the prospects for innovation in specific areas of enterprises, transfer their knowledge. However, mining engineers-practitioners, as a rule, do not have teaching experience and lectures, so they are reluctant to agree to participate in the educational process of universities (Horeshok et al, 2016).

The relevance of the formation of the innovative nature of the development of the mining industry in the country and the world is an important factor affecting the innovative training of specialists (Nikiforova, 2019). This made KuzSTU's integrative work on the implementation of the concept in the field of science development and scientific potential a priority in the following areas:

- formation of the University's innovation system based on strengthening ties with other universities in the country and the world;

- $\quad$ effective use of the results of scientific and technical activities;

- maintaining and developing the human potential of the region's scientific and technical complex;

- development of international scientific and technological progress;

- the development of fundamental science and most important applied research and development;

- integration of science and education, etc.

However, the training of specialists for the innovative mining industry of the country and the region is insufficient. in our opinion, it is more "supportive" than innovative in nature. In addition, the problem of training personnel for the innovative mining industry compounded by the fact that there is a demanding and complex nature of the industry itself, which complicates both the recruitment and training of specialists. In General, for the younger generation, working in the mining industry is as follows:

- having an unattractive image of the industry: young professionals and the younger generation in General still consider working in it dirty, dangerous and unpromising in terms of career aspirations;

- employers in the mining industry still rely on candidates with experience who can start work without delay, without training by a mentor, or without using a probationary period.

Our proposed model of integration of a technical University, bases on the example of the Federal state UNIVERSITY of higher education NAMED after T. F. Gorbachev (Kemerovo, Russia), with production for the purpose of training specialists for the innovative economy of the mining industry, does not claim to be exceptional, it requires its own development, but the main idea, the idea of integration, has found its definite resolution (fig. 1)

Based on the above, it is necessary to emphasize the importance and significance of specialist training for the mining industry in the higher education system on the basis of conceptual foundations that contribute to their formation as innovation - oriented specialists with competence in the field of innovation. 


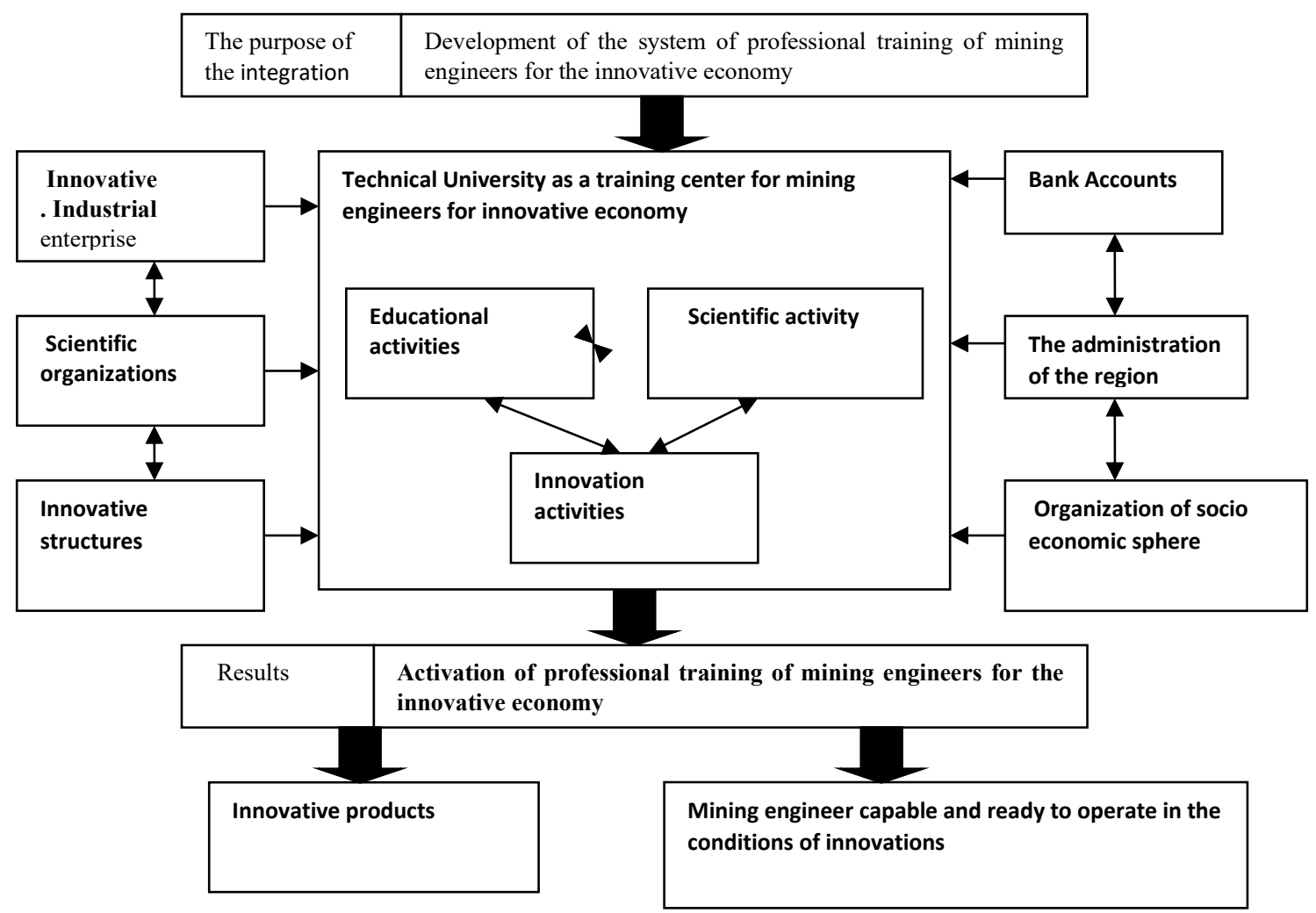

Fig. 1. Model of integration of a technical University with production in order to train specialists for the innovative economy

Thus, we have make an attempt to justify the relevance of finding ways to train personnel for the mining industry, which will be in demand in the labor market in the conditions of innovative development of the domestic economy.

\section{References}

1. Bulletin of the TRANS-Baikal mining College named after M. I. Agoshkov: Agoshkov readings (Chita, Zabgk, 2017)

2. I. Buzko, Y. Dyachenko, M. Petrova, N. Nenkov, D Tuleninova, K. Koeva, Artificial Intelligence Technologies in Human Resource Development. Computer Modelling and New Technologies, 20(2), 26 (2016)

3. A. Chupryakova, L. Zakonnova, M. Petrova, Benchmarking as a determinant of modern mining education, E3S Web of Conf., 174 (2020).

4. G. I. Gerasimov, L. V. Ilyukhina. "Innovations in education: essence and social mechanisms (sociological aspect)" (Rostov on/D, "Logos", 1999) 
5. I. Gryshova, M. Petrova, M. Tepavicharova, A. Diachenko, T .Gutsul, Entrepreneurship and Sustainability Issues, 7(1) (2019)

5. A. A. Horeshok, S. A. Zhironkin., O. V. Zhironkina., M. A Tyulenev, Mining science and technology, 1 (2016)

6. V. Jarmusevica, D. Ilisko, J Badjanova,. V. Jukss, M. Petrova, Proceedings of EDULEARN19 Conf. (2019)

7. V. Jarmusevica, D. Ilisko, J. Badjanova, V Jukss, M. Petrova, International Multidisciplinary Scientific Geo Conf. (2019)

8. I. Kolechkina, I Verchagina, E. Eltsova, M. Petrova. Ecologization of the Development Management of the Mining Regions of Russia, E3S Web of Conf., 134, 02004 (2019)

9 I. Linde, M. Petrova, CBU International conference proceedings 2018: Innovations in Science and Education (2018)

10. M. Petrova. M. Tepavicharova, L. Boykova, E3S Web of Conf, 41, 04017 (2018)

11. M. Petrova, V. Koval, M. Tepavicharova, A. Zerkal, A. Radchenko, N. Bondarchuk, Journal of Security and Sustainability Issues, 9(3) (2020)

12. A. Zagorodnya, N. Dichek, N..Chobitko, M. Voznyk, L. Honchar,. M. Petrova, International Journal of Higher Education, 9(3) (2020)

13. N. Zaruba, N. Egorova, In the collection: Coal in the 21 st Century: Mining, Processing and Safety (2016)

14. N. Zaruba., S. Kostyuk. N. Egorova, Proceedings of the V International scientific and practical conference (2016)

15. N. Zaruba, N. Egorov, P. Kosinskij. E3S web of conf., 04003 (2017)

16. N. Zaruba, O. Nikiforova, K Vostrikov, E3S Web of Conf, 5, 04007 (2020)

17. E. Zhernov, E Nekhoda,, M. Petrova, E3S Web of Conf., 174, 04003 (2020) 